\title{
PROGRAMA DE ACELERAÇÃO DO CRESCIMENTO (PAC): UM ESTUDO DESCRITIVO SOBRE OS DESPERDÍCIOS ATIVOS E PASSIVOS
}

\author{
GROWTH ACCELERATION PROGRAM (PAC): A DESCRIPTIVE STUDY OF ACTIVE \\ AND PASSIVE WASTE
}

\begin{abstract}
DANIELE SILVA RODRIGUES
Mestra em Administração com concentração na área Pública no Programa de Pós-Graduação em Administração da Universidade Federal de Viçosa (PPGADM/UFV). Endereço: Avenida Peter Henry Rolfs, s/n / Campus Universitário / 36570-900 / Viçosa/MG / Brasil. E-mail: silvar.daniele@gmail.com
\end{abstract}

\section{NÁLBIA DE ARAÚJO SANTOS}

Doutora em Controladoria e Contabilidade na Universidade de São Paulo (USP). Professora do Departamento de Administração e Contabilidade e do Programa de Mestrado Profissional em Administração Pública na Universidade Federal de Viçosa (UFV). Endereço: Avenida Peter Henry Rolfs, s/n / Campus Universitário / 36570-900 / Viçosa/MG / Brasil.

E-mail:nalbiaas@yahoo.com.br

\section{WALMER FARONI}

Doutor em Ciências Econômicas e Empresariais pela Universidade de Valência. Professor do Departamento de Administração e Contabilidade e do Programa de Pós-Graduação em Administração da Universidade Federal de Viçosa (PPGADM/UFV). Endereço: Avenida Peter Henry Rolfs, s/n / Campus Universitário / 36570-900 / Viçosa/MG / Brasil. E-mail: walmerfaroni@gmail.com

\section{RESUMO}

Em 2007, o governo brasileiro implementou o Programa de Aceleração do Crescimento (PAC), com o objetivo de incentivar o crescimento econômico do Brasil e investimentos nas áreas de saneamento, habitação, transporte, energia e recursos hídricos. Tal programa, em sua primeira etapa (2007-2010), contribuiu de modo determinante para o aumento da oferta de empregos e da geração de renda no Brasil. No entanto, de acordo com Instituto Trata Brasil, $86 \%$ das obras de esgotamento sanitário provenientes do PAC estavam paralisadas, atrasadas ou não iniciadas até dezembro de 2012. Ainda, em 2008 e 2009, por meio da edição especial do Programa de Fiscalização por Sorteios Públicos, a Controladoria Geral da União (CGU) constatou diversas irregularidades em 110 municípios brasileiros contemplados com recursos do PAC. Nesse contexto, o objetivo do estudo foi analisar as irregularidades constatadas pela CGU, na aplicação dos recursos federais destinados às áreas de saneamento e habitação dos municípios brasileiros por meio da primeira etapa do PAC. A principal fonte de dados da pesquisa foram os relatórios dos auditores da CGU advindos do PAC e dados do Censo 2000, disponibilizados pelo IBGE. Técnicas de análise de conteúdo foram utilizadas para classificar as irregularidades constatadas pela CGU em desperdício ativo (corrupção) e passivo (má gestão) e estatísticas descritivas para

\footnotetext{
${ }^{*}$ Resultados parciais deste artigo foram publicados no XI Congresso USP de Iniciação Científica em Contabilidade, realizado em julho de 2014 em São Paulo. E uma versão em espanhol foi publicada no Congresso Gigapp, realizado em Madrid, na Espanha em outubro de 2016.
} 
analisar o perfil das irregularidades e dos municípios auditados. Observou-se que os desperdícios mais frequentes nos municípios auditados são os classificados como Superfaturamento e Licitação Fraudada (classificados como desperdício ativo) e Má Administração e Licitação Irregular, na modalidade de desperdício passivo.

Palavras-chave: Auditoria pública. Desperdícios ativo e passivo. Programa de Aceleração do Crescimento. Controladoria Geral da União.

\begin{abstract}
In 2007, the Brazilian government implemented the Growth Acceleration of Program (PAC), with the objective of encouraging Brazil's economic growth, with investments in the areas of sanitation, housing, transportation, energy and water resources. This program, in its first phase (2007-2010), contributed in a decisive way to the increase in the supply of jobs and in the generation of income in Brazil. However, according to "Instituto Trata Brasil" $86 \%$ of the sanitary sewage works from the PAC were paralyzed, or delayed or not started until December 2012. Also, in 2008 and 2009, through the special edition of the Inspection Program by Public Sweepstakes, the Federal Comptroller General's Office found several irregularities in 110 Brazilian municipalities covered with PAC funds. In this context, the objective of the study was to analyze the irregularities verified by the CGU, in the application of the federal resources destined to the sanitation and housing areas of the Brazilian municipalities through the first stage of the PAC. The main source of data for the survey were CGU's reports from the PAC and Census 2000 data, made available by IBGE. The techniques of Content analysis were used to classify the irregularities, verified by the CGU, in active waste (corruption) and passive (mismanagement). The Descriptive statistics were used to analyze the profile of irregularities and the municipalities audited. It was observed that the most frequent wastes in the municipalities audited are those classified as Overbilling and Fraudulent Bidding (classified as active waste); and "Bad Administration" and "Irregular Bidding", in the form of passive waste.
\end{abstract}

Keywords: Public audit. Active and passive waste. Growth of Acceleration Program. General Comptroller of the Union.

\title{
1 INTRODUÇÃO
}

O processo de avaliação da execução de Programas de Governo é relevante para verificar o alcance dos objetivos e a adequação da gestão dos recursos federais. Esse tipo de avaliação é de competência da Secretaria Federal de Controle Interno (SFC), responsável por fiscalizar e avaliar "a execução de programas de governo, realizar auditorias e avaliar os resultados da gestão dos administradores públicos federais, apurar denúncias e representações; exercer o controle das operações de crédito; e, também, executar atividades de apoio ao controle externo" (Controladoria Geral da União [CGU], 2017a).

A SFC conta com a estrutura administrativa das unidades regionais da CGU para realizar as atividades de controle interno em todo o país. O foco do trabalho dos auditores da SFC é o aprimoramento da gestão e da execução das políticas públicas, com o objetivo de melhoria da prestação dos serviços públicos, bem como a defesa do patrimônio público e o incremento da transparência da gestão. Durante a realização dos trabalhos de auditoria os principais procedimentos são a análise das contas e documentos, a vistoria pessoal e física das obras e serviços em realização e, em situações que os auditores consideram relevantes, ocorre o contato com a população, de modo direto ou por intermédio dos conselhos comunitários e outras entidades organizadas. Esses procedimentos possibilitam coletar evidências sobre a legalidade e aferir os resultados da execução de Programas de Governo (CGU, 2017a).

Para dar transparência e publicidade aos resultados de seus trabalhos de auditoria, a CGU divulga essas evidências por meio de relatórios de auditoria e fiscalização. Os relatórios de fiscalização provenientes do Programa de Fiscalização por Sorteios Públicos (PFSP) apresentam a avaliação da efetiva aplicação dos recursos públicos federais destinados ao cumprimento da finalidade constante na ação governamental (CGU, 2017a). Esse tipo de 
relatório contém evidências úteis para traçar um diagnóstico das irregularidades encontradas pela CGU na execução dos recursos destinados ao cumprimento de políticas governamentais via Programas de Governo.

Essas evidências de inconformidade legal são utilizadas neste estudo para identificar indicadores de corrupção e de gestão inadequada dos recursos federais aplicados nos municípios via o Programa de Aceleração do Crescimento (PAC), programa para o qual, por recomendação da Presidência da República, foi realizada uma edição especial do PFSP, com o intuito de acompanhar a regularidade no uso de seus recursos e, assim, evitar desvios que poderiam comprometer a efetividade de suas ações (CGU, 2009). Assim, o objetivo do trabalho é-analisar as irregularidades constatadas pela Controladoria Geral da União, na aplicação dos recursos federais destinados às áreas de saneamento e habitação dos municípios brasileiros, por meio da primeira etapa do Programa de Aceleração do Crescimento.

O levantamento do perfil das irregularidades pode contribuir para a identificação e o aprimoramento de indicadores relevantes para a avaliação de desempenho do PAC e para a observação de tendências dos indicadores de desperdício ativo ou passivo no uso dos recursos destinados ao programa. Além disso, o estudo pode contribuir para analisar os resultados dos indicadores de desperdício ativo ou passivo de acordo com as características geográficas e populacionais dos municípios auditados pela CGU. Essa análise dos indicadores, considerando as características geográficas e populacionais dos municípios, pode sugerir prováveis suposições a serem exploradas em futuras pesquisas.

Esse tipo de análise é relevante em função da importância social do PAC e do volume de recursos investidos em tal programa - na primeira etapa do PAC os investimentos representaram cerca de $\mathrm{R} \$ 619$ bilhões, até 31 de dezembro de 2010, segundo o $11^{\circ}$ Balanço Completo do PAC (2007-2010) (Ministério do Planejamento, Orçamento e Gestão [MPOG], 2010). Além disso, de acordo com estudo do Instituto Trata Brasil (ITB), até 2012, apenas 14\% do total de 138 obras na área de saneamento relativas ao PAC, ou seja, 114 obras do PAC1 e 26 obras do PAC2, foram concluídas. Assim, até dezembro de 2012, $86 \%$ das obras de esgotamento sanitário estavam paralisadas, atrasadas ou ainda não iniciadas.

O estudo do ITB concluiu que os atrasos nas obras são reflexos de deficiências na qualidade dos projetos originalmente enviados ao governo federal, problemas nas licitações, burocracia no repasse dos recursos, lentidão no processo de concessão de licenças ambientais, ausência de coordenação entre as ações das esferas federal, estadual e municipal na programação e o foco na execução dos empreendimentos de maior porte, entre outros aspectos (ITB, 2013). Ademais, com base no último levantamento feito pelo ITB, em 2015, verifica-se que essa situação persistiu ao longo dos últimos anos, tendo em vista que até 2015 somente 32\% das obras de esgotamento sanitário do PAC estavam concluídas (ITB,2016).

O cenário citado indica possíveis problemas de má gestão e de inconformidade legal na aplicação dos recursos federais do PAC, no segundo caso, em especial, quando sugere haver problemas nas licitações. Logo, entender os mecanismos de fraude e, consequentemente, os tipos de desperdícios, que possam ter ocorrido na gestão do PAC, pode auxiliar na compreensão do modo de operação de corruptos na esfera municipal. Desse modo, espera-se, com os resultados do estudo, contribuir para o aprimoramento de possíveis indicadores a serem usados na avaliação da execução de Programas de Governo.

Este trabalho tem mais cinco seções, além desta introdução. As próximas seções apresentam um breve histórico do PAC e uma revisão da literatura sobre o tema proposto. A quarta abrange os procedimentos metodológicos realizados no estudo para atender aos objetivos propostos. A quinta descreve os resultados encontrados. Por fim, na sexta seção são apresentadas as conclusões obtidas com base nos resultados desta pesquisa.

\section{PROGRAMA DE ACELERAÇÃO DO CRESCIMENTO - PAC}

O Programa de Aceleração do Crescimento (PAC), de iniciativa do Governo Federal, foi difundido no ano de 2007, com o intuito de incentivar o crescimento econômico do Brasil, com investimentos nas áreas de saneamento, habitação, transporte, energia e recursos hídricos. Por meio do PAC, o principal objetivo do Governo foi aumentar os investimentos em infraestrutura, 
para eliminar os principais gargalos que limitam o crescimento econômico, e proporcionar o aumento da produtividade das empresas, além de estimular o crescimento do investimento privado e a redução das desigualdades regionais. Os recursos federais do PAC, em geral, foram transferidos para órgãos federais, estaduais, municipais ou entidades legalmente habilitadas para serem aplicados em projetos específicos no Município e atender a determinadas políticas públicas (MPOG, 2017).

Segundo o MPOG (2017), desenvolvido como um plano estratégico para retomar o planejamento e os investimentos em setores estruturais do país, na sua primeira etapa, o PAC contribuiu de modo determinante para o aumento da oferta de empregos e para a geração de renda, e elevou o investimento público e privado em obras fundamentais. De acordo com os dados do MPOG, nos seus anos iniciais (2007-2010), o PAC ${ }^{1}$ contribuiu para aumentar os investimentos públicos brasileiros - o PIB (que era de 1,62\%, em 2006, passou para 3,27\%, em 2010) e para geração de novos postos de empregos (foram criados 8,2 milhões de postos de trabalho durante o seu período de execução). Para o Ministério do Planejamento o PAC foi importante para o país durante a grave crise financeira mundial entre 2008 e 2009, visto que garantiu emprego e renda aos brasileiros. Por conseguinte, contribuiu para a continuidade do consumo de bens e serviços. Manteve ativa a economia e reduziu os efeitos dessa crise sobre as empresas nacionais.

Ademais, conforme o 11을 Balanço Completo da primeira etapa do PAC (2007-2010), divulgado em dezembro de 2010, inicialmente o programa previu investimentos no montante de $\mathrm{R} \$ 657,4$ bilhões para o período de 2007 a 2010 . Até outubro de 2010 , foram investidos $\mathrm{R} \$ 559,6$ bilhões, $85,1 \%$ do total previsto. Nas áreas de habitação e saneamento básico, foram destinados em torno de $R \$ 215,6$ e $R \$ 40$ bilhões para serem investidos em tais áreas, respectivamente (MPOG, 2010).

\section{ESTUDOS ANTERIORES}

Existem estudos que utilizaram indicadores de corrupção e má gestão para analisar a inadequada gestão dos recursos públicos tanto no âmbito internacional como no contexto brasileiro. Por exemplo, na literatura internacional apresentam-se os trabalhos de Hart, Shleifer e Vishny (1997), Di Tella e Schargrodsky (2003) e Bandiera, Prat e Valletti (2009). No âmbito nacional citam-se os estudos realizados por Mendes (2004), Ferraz, Finan e Moreira (2008), Vieira (2011), Dias, Matias-Pereira, Farias e Pamplona (2013), Marin, Gama e Campelo (2014) e Caldas, Costa e Pagliarussi (2016).

No âmbito da literatura internacional, Hart et al. (1997) investigaram quando seria benéfico o próprio governo prestar o serviço prisional ou optar por terceirizar por meio de instituições privadas, no contexto dos Estado Unidos. Os autores desenvolveram um modelo matemático para analisar a relação entre o custo x benefício de prestar diretamente ou terceirizar os serviços de prisões. Esse modelo considerou a existência de gestores corruptos nesse tipo de decisão. Em relação ao comportamento corrupto do gestor público, os autores argumentaram que em situações em que os problemas de favorecimento a empresas privadas em contratos públicos são maiores que os problemas de patrocínio a grupos de interesses (fornecimento de empregos a trabalhadores que apoiaram o político na eleição) é mais indicada a prestação de serviço pelo próprio governo. Em contrapartida, a privatização do serviço público é mais adequada quando os problemas de patrocínio a grupos de interesses são maiores que os problemas de favorecimento a empresas privadas em contratos públicos.

Di Tella e Schargrodsky (2003) desenvolveram um estudo que teve como objeto de pesquisa os setores de compras dos hospitais públicos da cidade de Buenos Aires, Argentina, durante 1996 e 1997. O objetivo da pesquisa foi investigar a relação entre os preços pagos por insumos básicos hospitalares, o valor dos salários pagos aos funcionários responsáveis pela aquisição desses insumos e a implementação de uma política, pelo governo local, de combate à corrupção no referido setor. Os resultados da pesquisa apontaram uma redução de aproximadamente $10 \%$ dos preços pagos pelos insumos em decorrência da repressão à corrupção, que ocorreu por meio de auditorias hospitalares. Ademais, quanto à relação dos preços pagos pelos insumos com os salários dos funcionários responsáveis pelo setor de 
compras dos hospitais, os autores concluíram que é necessária a aplicação, em conjunto, de uma política que vise à melhoria salarial desses funcionários e a intensificação das auditorias de combate à corrupção, a fim de melhorar a eficiência nas compras de tal setor.

Ainda, no contexto internacional, Bandiera et al. (2009) desenvolveram um arcabouço teórico para estudar as características dos gastos desnecessários que ocorrem na administração dos recursos públicos na Itália. Os autores classificaram tais gastos em duas categorias: desperdício ativo e desperdício passivo. A primeira, o desperdício ativo, também denominado de corrupção, ocorre quando um agente público obtém benefícios diretos ou indiretos para si, causando prejuízos ao ente público. Já na segunda categoria, denominada de desperdício passivo ou ineficiência, os agentes públicos não obtêm vantagens diretas ou indiretas para si. Tal desperdício é proveniente de diversos fatores, tais como: o excesso de regulação no setor público e a falta de funcionários públicos competentes e incentivados a minimizarem os custos em aquisições feitas pela administração pública.

Após a construção do arcabouço teórico sobre desperdício ativo e passivo, Bandiera et al. (2009) verificaram empiricamente se esses desperdícios são determinantes do custo dos produtos comprados por órgãos públicos italianos. Para tanto, os autores analisaram 21 itens adquiridos por 447 funcionários responsáveis pelo setor de compras de diversos órgãos públicos italianos, no período 2000-2005. Utilizando-se de técnicas estatísticas, Bandiera et al. (2009) desenvolveram um modelo matemático para analisar o impacto das duas formas de desperdício no preço do produto adquirido. Constatou-se que, do total de desperdícios ativos e passivos, que ocorreram na compra de bens realizada por órgãos públicos italianos, em média, $83 \%$ dos gastos dispensáveis aconteceram em virtude do desperdício passivo (ineficiência da gestão pública). Quanto a isso, os autores esclarecem que tal resultado não indica que a corrupção não seja uma questão importante na administração dos recursos públicos. O intuito, segundo eles, é evidenciar um tipo de desperdício que recebe pouca atenção dos órgãos públicos e que ocorre com frequência na gestão desses recursos, causando prejuízo para o setor público.

No Brasil, o estudo de Mendes (2004) teve como objetivo analisar o perfil das irregularidades presentes na gestão municipal do Fundo de Manutenção e Desenvolvimento do Ensino Fundamental e de Valorização do Magistério (FUNDEF). Para tanto, o autor utilizou-se das constatações presentes nos relatórios do $1^{\circ}$ ao $9^{\circ}$ sorteio do Programa de Fiscalização a Partir de Sorteios Públicos (PFSP) da CGU, referentes a 67 municípios que foram contemplados com recursos do FUNDEF. Os resultados da pesquisa demonstraram que 18 tipos de irregularidades ocorreram na gestão municipal do FUNDEF. As mais corriqueiras são as seguintes irregularidades: Ineficácia do Conselho de Acompanhamento e Controle Social do FUNDEF (73\%), Desvios de Recursos da parcela de 40\% do FUNDEF (63\%), Desvio de Finalidade para despesas não caracterizadas como ensino regular (60\%), Baixa Qualidade de Controle Gerencial (52\%) e Indícios de Fraudes em Processos Licitatórios (43\%).

Ferraz et al. (2008) analisaram os efeitos da corrupção e da má gestão, ocorridas nos gastos com educação, sobre o desempenho dos alunos do ensino fundamental. As principais fontes de dados que os autores utilizaram foram os resultados da prova Brasil, referente ao ano de 2005, e os relatórios de auditorias provenientes do PFSP, concernentes aos sorteios 2 ao $16^{2}$. A primeira fonte de dados foi empregada como proxy das habilidades cognitivas dos alunos, enquanto que a segunda foi utilizada para a construção de indicadores de corrupção e má gestão, por meio da classificação das constatações presentes nos relatórios de auditoria em uma das 20 categorias preestabelecidas pelos autores. A fim de atingir o objetivo proposto, os autores desenvolveram um modelo de função de produção educacional, incorporados os efeitos da corrupção e da má gestão. Constatou-se que, controlada por outras características, a corrupção reduz significativamente o desempenho dos discentes na prova Brasil e afeta negativamente outros indicadores escolares, tais como a taxa de aprovação e a taxa de abandono dos estudantes.

Vieira (2011), em seu estudo, analisou as características das improbidades (corrupção) na administração pública municipal e investigou as possíveis causas e efeitos dessas improbidades. Para identificar as improbidades ocorridas na gestão pública municipal, os autores classificaram as constatações presentes nos relatórios de auditorias, oriundos dos sorteios $20^{\circ}$ ao $30^{\circ}$ do PFSP, em: informações e comentários, falhas formais, falhas médias e falhas graves. Feito isso, pautando-se nas principais hipóteses descritas na literatura e utilizando alguns testes 
estatísticos, o autor analisou empiricamente as causas e efeitos da corrupção no setor público. Os principais resultados evidenciaram que o grau de irregularidade difere significativamente entre as regiões político-administrativas do país e que a corrupção tem associação negativa com o desenvolvimento socioeconômico dos municípios e com capacidades institucionais de controle de oportunismo.

Dias et al. (2013), pautando-se no arcabouço teórico sobre desperdício ativo e passivo apresentado no trabalho de Bandiera et al. (2009) e nas variáveis utilizadas na pesquisa de Ferraz et al. (2008), desenvolveram um estudo com o intuito de identificar os fatores de desperdício ativo (corrupção) e passivo (ineficiência) relacionados com as irregularidades que ocorreram nos gastos com saúde, provenientes das transferências da União para os municípios brasileiros. Para tanto, as constatações presentes nos relatórios de auditorias do PFSP, derivados do $31^{\circ}$ e $32^{\circ}$ sorteio, foram classificadas em desperdício ativo ou passivo. Os autores utilizaram as mesmas variáveis empregadas no estudo de Ferraz et al. (2008) para identificar os desperdícios ativos e passivos nos relatórios de auditoria da CGU. Por meio da técnica estatística multivariada análise fatorial foram identificados três fatores de desperdício passivo estaticamente associados com as irregularidades que ocorreram nos gastos com saúde nos municípios auditados. São elas: Inadequabilidade Administrativa, Fraca Fiscalização e Baixo Nível de Compliance. Já, para o desperdício ativo, não foi possível apresentar um fator que o representasse, uma vez que os dados da pesquisa não apresentaram níveis adequados de significância. Ainda, o estudo apontou para a necessidade de maior preocupação, por parte dos órgãos responsáveis, da academia e da população, com o desperdício passivo, que, assim como o desperdício ativo, afeta significativamente a qualidade dos serviços prestados. Ademais, os autores destacaram a necessidade premente de "implantação de mecanismos de governança no setor público, os quais poderiam reduzir o desperdício ativo e passivo" (Dias et al., 2013, p. 206).

Marin et al. (2014) investigaram os tipos de desperdício ativo e passivo que ocorreram na aplicação dos recursos federais destinados aos municípios do Estado do Pará para o desenvolvimento de programas e ações coordenadas pelo Ministério das Cidades. Os autores utilizaram 21 categorias, as mesmas empregadas no estudo de Dias et al. (2013), com a incorporação da variável "Falta de Publicidade", para classificarem as constatações presentes nos relatórios de auditorias, provenientes do PSFP, em desperdício ativo e passivo. O universo de análise da pesquisa foram 23 relatórios de auditorias realizadas nos municípios paraenses no

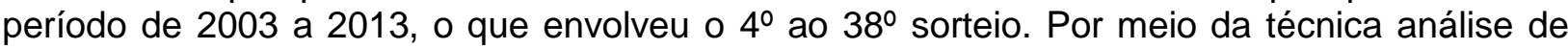
conteúdo e da quantificação percentual das irregularidades presentes nos relatórios de auditoria, os autores constataram que os dois tipos de desperdícios estão presentes na amostra analisada. Os mais frequentes são: o Desvio de Recurso (19\%), classificado como desperdício ativo; e Licitação Irregular (38\%) e Falta de Publicidade (31\%), classificados como desperdício passivo.

Por fim, o trabalho de Caldas et al. (2016) teve como objetivo investigar a relação entre corrupção e composição dos gastos governamentais nos municípios brasileiros. As principais fontes de dados utilizadas pelos autores foram os relatórios de auditorias do $20^{\circ}$ ao $30^{\circ}$ sorteio do Programa de Fiscalização por Sorteios Públicos da CGU, as transferências de recursos da União disponíveis no Portal da Transparência do Governo Federal e dados contábeis das despesas dos municípios obtidos no site da Secretaria do Tesouro Nacional (FINBRA). A primeira fonte de dados foi utilizada para construir medidas de corrupção. Para tanto, os autores utilizaram somente as constatações classificadas pelos auditores da CGU em falhas médias e falhas graves. Já a segunda e a terceira fonte de dados foram empregadas para descrever a composição das transferências da União para municípios e das despesas municipais. Constatouse, por meio de modelos econométricos de regressão múltipla, que existe associação entre a ocorrência de corrupção e os gastos com assistência social, educação, saúde e outras funções. No caso dos gastos com educação e saúde, os autores destacam que essa relação foi significativamente positiva. Indicam que maiores níveis de corrupção nos municípios ocasionam maiores gastos com educação e saúde. 


\section{PROCEDIMENTOS METODOLÓGICOS}

\subsection{Descrição da fonte de dados}

A principal fonte de dados da pesquisa foram os relatórios dos auditores da CGU advindos da edição especial do Programa de Fiscalização por Sorteios Públicos (PFSP). Em tal edição, que ocorreu em 2008 e 2009, os municipios selecionados foram fiscalizados exclusivamente quanto à aplicação de recursos do Programa de Aceleração do Crescimento (PAC), envolvidas as áreas de saneamento e habitação. Foram realizados dois sorteios que selecionaram municípios com até 500 mil habitantes, exceto as capitais, 50 municípios no ano de 2008 e 60 municípios no ano de 2009, equivalendo a 110 municípios. O universo de análise desta pesquisa foi composto por 108 desses municípios sorteados e auditados, em virtude de dois relatórios não estarem disponíveis no sistema da CGU (CGU, 2017b).

Outra fonte de dados utilizada foi o Censo 2000, desenvolvido pelo Instituto Brasileiro de Geografia e Estatística (IBGE). Os dados do Censo 2000 foram empregados com o objetivo de identificar o perfil socioeconômico e geográfico dos municípios analisados e, assim, complementar as informações contidas nos relatórios de auditoria. Esses dados permitiram realizar uma análise descritiva detalhada dos resultados obtidos na análise de conteúdo dos relatórios de auditoria com o perfil socioeconômico e geográfico dos municípios da amostra. $\mathrm{A}$ análise descritiva possibilitou relacionar os indicadores de desperdícios ativos e passivos, obtidos na análise de conteúdo, com o contexto dos municípios na época em que foram auditados pela CGU.

Ressalta-se que os relatórios de fiscalização foram escolhidos porque permitiram coletar informações relativas à aplicação dos recursos públicos federais do PAC nos municípios brasileiros, já que as auditorias foram realizadas com base em visita in loco. Essas visitas têm como objetivos examinar as contas e documentos, realizar inspeção pessoal e física das obras e serviços em realização, além de coletar informações da população por meio de entrevistas e questionários. Por conseguinte, os relatórios de fiscalização incluem informações concernentes a quantidade de fiscalizações realizadas e ao montante de recursos aplicados, além de apontarem as irregularidades contidas nas obras. Assim, com base nessas informações, foi possível fazer o levantamento dos desperdícios ativos e passivos ocorridos nas obras do PAC, nas áreas de saneamento e habitação.

\subsection{Análise do conteúdo}

A interpretação do conteúdo dos relatórios de auditoria da GCU foi fundamentada na técnica de análise de conteúdo. O principal método de análise foi o categorial. Esclarece que, segundo Bardin (1977, p.27), a análise de conteúdo "é um conjunto de técnicas de análise das comunicações" e o método de análise categorial consiste em um processo de classificação.

Para aplicar o método de categorização foram consideradas as variáveis citadas nos estudos de Ferraz et al. (2008), Dias et al. (2013) e Marin et al. (2014). Este estudo fundamentouse em 21 tipos de irregularidades, agrupadas nas categorias desperdício ativo e passivo, para desenvolver a análise de conteúdo usado o método de categorização. A Tabela 1 descreve as variáveis utilizadas para classificar os tipos de desperdícios (ativo ou passivo):

Tabela 1

Categoria de Desperdícios Ativos e Passivos

\begin{tabular}{ll}
\hline \multicolumn{1}{c}{ Constructos } & Desperdício Ativo \\
\hline Superfaturamento & \multicolumn{1}{c}{ Descrição } \\
\hline Licitação com Desvio de Recursos & $\begin{array}{l}\text { Ocorre quando os preços pagos estão acima dos preços de } \\
\text { mercado, ou quando a quantidade comprada excede em muito as } \\
\text { necessidades do município. }\end{array}$ \\
\hline Desvio de Recursos & $\begin{array}{l}\text { Ocorre quando existe evidência de que o serviço licitado e pago } \\
\text { não foi prestado. }\end{array}$ \\
\hline & $\begin{array}{l}\text { Ocorre nos casos em que há despesas sem comprovação da } \\
\text { parte física ou serviço prestado. }\end{array}$ \\
\hline
\end{tabular}


Tabela 1 (continuação)

\begin{tabular}{|c|c|}
\hline \multicolumn{2}{|c|}{ Desperdício Passivo } \\
\hline Constructos & Descrição \\
\hline Licitação Fraudada & $\begin{array}{l}\text { Ocorre quando o agente executor, na licitação, usa parente ou } \\
\text { terceiros em benefício próprio ou para beneficiar outros. }\end{array}$ \\
\hline Não pagamento do tributo & Ocorre quando a prefeitura deixa de pagar algum tributo. \\
\hline Não execução de recurso & $\begin{array}{l}\text { Ocorre quando a União repassa o dinheiro, mas o município não } \\
\text { o utiliza. }\end{array}$ \\
\hline Obra inacabada ou com execução irregular & $\begin{array}{l}\text { Ocorre quando o órgão responsável deixa uma obra inacabada e } \\
\text { paga a parcela correspondente (obra paralisada). }\end{array}$ \\
\hline Inexistência ou fraca atuação do conselho & $\begin{array}{l}\text { Ocorre quando o conselho não demonstra atuar na fiscalização } \\
\text { dos gastos da área. }\end{array}$ \\
\hline Clientelismo & $\begin{array}{l}\text { Ocorre quando o prefeito gasta recurso público com a finalidade } \\
\text { explícita de conseguir votos. }\end{array}$ \\
\hline Execução Irregular de programas sociais & $\begin{array}{l}\text { Ocorre quando o controle ou o cadastro dos programas sociais } \\
\text { encontra-se irregular. }\end{array}$ \\
\hline Elefante Branco & $\begin{array}{l}\text { Ocorre quando há uma construção ou compra de bem } \\
\text { desproporcional às necessidades do município. }\end{array}$ \\
\hline Licitação Irregular & $\begin{array}{l}\text { Ocorre quando existe alguma irregularidade nos documentos da } \\
\text { licitação. }\end{array}$ \\
\hline Licitação Fracionamento & $\begin{array}{l}\text { Ocorre quando o agente executor fraciona as despesas a serem } \\
\text { realizadas em diferentes licitações objetivando alterar o tipo de } \\
\text { licitação necessário, segundo regulamento previsto em lei. }\end{array}$ \\
\hline Licitação com Falta de concorrência & $\begin{array}{l}\text { Ocorre quando a licitação realizada não apresenta um mínimo de } \\
3 \text { concorrentes. }\end{array}$ \\
\hline Desvio de Finalidade para um mesmo setor & $\begin{array}{l}\text { Ocorre quando o recurso é usado para as obras do PAC, mas em } \\
\text { objetivo diverso do que inicialmente acordado com a União. }\end{array}$ \\
\hline Desvio de Finalidade para outro setor & $\begin{array}{l}\text { Ocorre quando o recurso é usado em outro setor, em objetivo } \\
\text { diverso do que inicialmente acordado com a União. }\end{array}$ \\
\hline Não ocorreu contrapartida & $\begin{array}{l}\text { Ocorre quando o município não disponibiliza a contrapartida de } \\
\text { sua responsabilidade. }\end{array}$ \\
\hline Falta de Publicidade & $\begin{array}{l}\text { Ocorre quando o prefeito não notifica os partidos políticos, } \\
\text { sindicatos de trabalhadores e entidades empresariais, quanto ao } \\
\text { repasse de verba advinda da União para execução de obras no } \\
\text { município. }\end{array}$ \\
\hline Obra acabada com irregularidade & $\begin{array}{l}\text { Ocorre quando a obra é feita em sua totalidade, mas existem } \\
\text { algumas pequenas irregularidades. }\end{array}$ \\
\hline $\begin{array}{l}\text { Irregularidade não relacionada ao agente } \\
\text { executor }\end{array}$ & $\begin{array}{l}\text { Ocorre quando há irregularidades que não estão sob a } \\
\text { responsabilidade do agente executor. }\end{array}$ \\
\hline Má Administração & $\begin{array}{l}\text { Qualquer outra irregularidade apontada pela CGU que não se } \\
\text { enquadra nos outros critérios acima, e traz como consequência a } \\
\text { piora na prestação do serviço público e o não atingimento do } \\
\text { objetivo do programa. }\end{array}$ \\
\hline
\end{tabular}

Nota. Fonte: Adaptado de Ferraz, C., Finan; F., \& Moreira, D. B. (2008). Corrupção, má gestão, e desempenho educacional: evidências a partir da fiscalização dos municípios. Anais do Encontro Nacional de Economia, Salvador, BA, Brasil, 36. Dias, L. N. S., Matias-Pereira, J., Farias, M. R. S., \& Pamplona, V. M. S. (2013). Fatores Associados ao Desperdício de Recursos da Saúde Repassados pela União aos Municípios Auditados pela Controladoria Geral da União. R. Cont. Fin-USP, 24(63), 206-218. Marin, T. I. S., Gama, D. S. S., \& Campelo, S. (2014). Corrupção e Ineficiência nos Repasses Federais: uma análise dos gastos do Ministério das Cidades nos Municípios Paraenses (2003-2013). Anais do Congresso USP de Iniciação Científica em Contabilidade, São Paulo, SP, Brasil, 11.

Ressalta-se que o termo desperdício é definido neste estudo como toda irregularidade que resulte na perda de recursos públicos, seja pela ação de má gestão ou de corrupção. Para distinguir as categorias desperdícios ativos e desperdícios passivos foram empregadas as definições utilizadas por Dias et al. (2013). Assim, desperdício ativo ocorre quando "o ente privado obtém vantagem financeira em detrimento do prejuízo financeiro causado ao ente público" (Dias et al., 2013, p. 207) e é também denominado de corrupção. Já desperdício passivo ocorre "quando o erário público é lesado, no entanto não há o benefício financeiro do ente privado em contrapartida" (Dias et al., 2013, p. 207) e é considerado como ineficiência ou má gestão. No caso das subcategorias, o estudo de Ferraz et al. (2008) foi a principal base para identificar 20 tipos de irregularidades, que foram agrupadas nas categorias corrupção (desperdício ativo) e má gestão (desperdício passivo). Acrescentou-se uma nova variável na categoria desperdício passivo, denominada "Falta de Publicidade", definida por Marin et al. (2014), que também se basearam no estudo de Dias et al. (2013). 


\section{APRESENTAÇÃO DOS RESULTADOS}

\subsection{Descrições dos municípios}

São descritas na Tabela 2 as principais características dos municípios analisados. A amostra de municípios representa os valores auditados de aproximadamente $R \$ 307,58$ e 261,58 milhões, gerando 117 e 133 Ordens de Serviços (OS) para os auditores da CGU, nos anos de 2008 e 2009, respectivamente. Esses valores auditados estão distribuídos por pasta ministerial, $\mathrm{R} \$ 235.912 .624,77$ e $R \$ 219.180 .822,73$ para o Ministério das Cidades, com 58 e 80 OS; $R \$$ 61.802.315,27 e $R \$$ 35.524.889,78 para o Ministério da Saúde, com 52 e 47 OS, e $\mathrm{R} \$ 307.580 .208,07$ e $\mathrm{R} \$ 9.865 .268,03$ para o Ministério da Integração Nacional, com 7 e 6 OS, respectivamente, para os anos de 2008 e 2009.

Tabela 2

Valor auditado, número de Ordem de Serviços (OS) e localização dos municípios

\begin{tabular}{lcc}
\hline \multicolumn{1}{c}{ Ano } & $\mathbf{2 0 0 8}$ & $\mathbf{2 0 0 9}$ \\
\hline $\mathbf{N}$ ㅇ Total de OS & 117 & 133 \\
Valor total auditado (R\$) & $307.580 .208,07$ & $261.580 .653,41$ \\
Total de Municípios & & \\
\multicolumn{1}{c}{ Localização } & & 4 \\
Centro-Oeste & 4 & 25 \\
Nordeste & 23 & 7 \\
Norte & 6 & 14 \\
Sudeste & 8 & 9 \\
Sul & 8 & \\
\hline
\end{tabular}

Nota. Fonte: Dados da pesquisa.

Os valores médios das características socioeconômicas da população dos municípios auditados e do total do Brasil são demonstrados na Tabela 3. Essas médias mostram o quanto, na maioria dos indicadores, os municípios auditados se diferenciam da média dos municípios brasileiros. De modo geral, os dados evidenciam que os municípios auditados apresentam índices socioeconômicos médios inferiores, se comparados com a média nacional. Isso evidencia que os municípios auditados apresentam condições socioeconômicas inferiores à média do país.

Tabela 3

Características socioeconômicas médias da população dos municípios auditados e as médias gerais dos municípios brasileiros

\begin{tabular}{lcccccc}
\hline \multirow{2}{*}{ Indicadores } & \multicolumn{2}{c}{ Auditados 2008} & \multicolumn{2}{c}{ Auditados 2009 } & \multicolumn{2}{c}{ Brasil } \\
& Média & $\begin{array}{c}\text { Desvio } \\
\text { Padrão }\end{array}$ & Média & $\begin{array}{c}\text { Desvio } \\
\text { Padrão }\end{array}$ & Média & $\begin{array}{c}\text { Desvio } \\
\text { Padrão }\end{array}$ \\
\hline Expectativa de anos de estudo & 8,07 & 1,68 & 7,95 & 1,79 & 8,34 & 1,80 \\
\hline $\begin{array}{l}\text { Taxa de analfabetismo - 11 a } \\
\text { 14 anos }\end{array}$ & 9,74 & 8,36 & 10,17 & 9,18 & 7,52 & 8,23 \\
\hline $\begin{array}{l}\text { Taxa de analfabetismo - 18 } \\
\text { anos ou mais }\end{array}$ & 26,27 & 14,13 & 25,95 & 14,49 & 23,56 & 13,52 \\
\hline GINI & 0,55 & 0,06 & 0,55 & 0,06 & 0,55 & 0,07 \\
\hline$\%$ de extremamente pobres & 24,12 & 17,46 & 24,79 & 17,56 & 20,69 & 17,21 \\
\hline$\%$ de pobres & 45,26 & 23,11 & 45,86 & 23,71 & 41,06 & 22,78 \\
\hline$\%$ de vulneráveis à pobreza & 67,23 & 20,88 & 67,00 & 21,97 & 63,90 & 20,71 \\
\hline Renda per capita $(\mathrm{R} \$)$ & 306,47 & 185,85 & 315,15 & 197,70 & 338,54 & 192,44 \\
\hline THEIL & 0,52 & 0,11 & 0,52 & 0,11 & 0,51 & 0,14 \\
\hline
\end{tabular}


Tabela 3 (continuação)

\begin{tabular}{|c|c|c|c|c|c|c|}
\hline \multirow[b]{2}{*}{ Indicadores } & \multicolumn{2}{|c|}{ Auditados 2008} & \multicolumn{2}{|c|}{ Auditados 2009} & \multicolumn{2}{|c|}{ Brasil } \\
\hline & Média & $\begin{array}{l}\text { Desvio } \\
\text { Padrão }\end{array}$ & Média & $\begin{array}{l}\text { Desvio } \\
\text { Padrão }\end{array}$ & Média & $\begin{array}{l}\text { Desvio } \\
\text { Padrão }\end{array}$ \\
\hline $\begin{array}{l}\text { \% da população em domicílios } \\
\text { com banheiro e água encanada }\end{array}$ & 55,36 & 29,85 & 54,74 & 32,28 & 62,66 & 30,93 \\
\hline $\begin{array}{l}\text { \% da população em domicílios } \\
\text { com densidade }>2\end{array}$ & 42,58 & 15,19 & 43,61 & 14,99 & 38,14 & 14,92 \\
\hline $\begin{array}{l}\text { \% da população em domicílios } \\
\text { com coleta de lixo }\end{array}$ & 76,46 & 29,57 & 76,05 & 27,21 & 79,20 & 25,59 \\
\hline $\begin{array}{l}\text { \% da população em domicílios } \\
\text { com energia elétrica }\end{array}$ & 84,19 & 16,88 & 84,14 & 17,45 & 86,61 & 17,03 \\
\hline $\begin{array}{l}\text { \% de pessoas em domicílios } \\
\text { com abastecimento de água e } \\
\text { esgotamento sanitário } \\
\text { inadequados }\end{array}$ & 15,43 & 15,40 & 18,19 & 20,02 & 13,47 & 15,60 \\
\hline $\begin{array}{l}\text { Índice de Desenvolvimento } \\
\text { Humano Municipal (IDHM) }\end{array}$ & 0,50 & 0,10 & 0,51 & 0,11 & 0,52 & 0,10 \\
\hline População Rural & $10.534,73$ & $13.591,49$ & $7.114,31$ & $5.525,55$ & $5.722,38$ & $10.370,68$ \\
\hline População Total & $40.415,29$ & $63.663,78$ & $37.942,29$ & $72.744,20$ & $30.511,96$ & $185.672,80$ \\
\hline População Urbana & $29.880,55$ & $57.784,69$ & $30.827,98$ & $71.827,02$ & $24.789,57$ & $178.967,49$ \\
\hline
\end{tabular}

Nota. Fonte: Dados da pesquisa.

O perfil informado na Tabela 3 é complementado com as análises apresentadas nas tabelas a seguir. Observa-se na Tabela 4 que mais de 50\% dos municípios analisados têm Índice de Desenvolvimento Humano (IDH) baixo ou muito baixo. Ainda, verifica-se que os municípios da amostra são mais carentes do que a média nacional.

Tabela 4

Distribuição percentual dos municípios por faixas do Índice de Desenvolvimento Humano dos municípios auditados e as médias do total de municípios do Brasil

IDHM

\begin{tabular}{lccc}
\hline Classificação & \% dos Auditados em 2008 & \% de municípios em 2009 & \% do Brasil \\
Muito Baixo & 46,94 & 57,63 & 41,80 \\
Baixo & 30,61 & 16,95 & 29,7 \\
Médio & 20,41 & 22,03 & 26,1 \\
Alto & 2,04 & 3,39 & 2,4 \\
Muito Alto & 0 & 0 & 0 \\
\hline
\end{tabular}

Nota. Fonte: Dados da pesquisa.

Faixas IDHM: Muito Baixo: 0 a 0,499; Baixo: 0,500 a 0,599; Médio: 0,600 a 0,699; Alto: 0,700 a 0,799; Muito Alto: 0,800 a 1 .

As médias dos Índices GINI e THEIL, apresentadas na Tabela 3, indicaram que os municípios da amostra apresentam um nível elevado de desigualdade e concentração de renda, respectivamente. Essa constatação é complementada com as informações contidas na Tabela 5. Demonstra que a maioria dos municípios analisados apresentava uma renda per capita abaixo do salário mínimo em 2008 e 2009, que era de aproximadamente $\mathrm{R} \$ 465,00$.

Tabela 5

Distribuição percentual dos municípios por faixas da Renda per capita domiciliar média 2008

\begin{tabular}{lcc} 
Faixa $(\mathrm{R} \$)$ & № de municípios & \% de municípios \\
\hline 103,91 a 158,92 & 12 & 24,5 \\
158,93 a 239,45 & 13 & 26,5 \\
239,46 a 449,92 & 12 & 24,5 \\
449,93 a 899,91 & 12 & 24,5 \\
\hline
\end{tabular}


Tabela 5 (continuação)

\begin{tabular}{|c|c|c|}
\hline \multicolumn{3}{|c|}{2009} \\
\hline Faixa $(R \$)$ & № de municípios & $\%$ de municípios \\
\hline 86,79 a 150,36 & 15 & 25,4 \\
\hline 150,37 a 233,83 & 15 & 25,4 \\
\hline 233,84 a 442,80 & 15 & 25,4 \\
\hline 442,81 a 830,87 & 14 & 23,7 \\
\hline
\end{tabular}

Nota. Fonte: dados da pesquisa.

Ainda, na Tabela 6, é possível notar que a expectativa de anos de estudo para a população com até 18 anos de idade dos municípios auditados foi equânime nas faixas apresentadas. Todavia, a maioria das faixas ficaram abaixo de 11 anos. Indica que a maior parte da população com até 18 anos de idade da amostra não chega a completar o ensino médio. Esse contexto se agrava, se comparado com a taxa média de analfabetismo para a população da amostra com 18 anos ou mais, informada na Tabela 3, na qual, se verifica que $26,27 \%$ e $25,95 \%$ da população dos municípios analisados, respectivamente, nos anos de 2008 e 2009, não sabem ler nem escrever um simples bilhete.

Tabela 6

Distribuição percentual dos municípios por faixas de expectativa de anos de estudo até os 18 anos de idade

\begin{tabular}{lcc} 
& Faixa & \multicolumn{2}{c}{$\mathbf{2 0 0 8}$} & \\
\hline 4,75 a 6,70 & No de municípios & \% de municípios \\
6,71 a 8,13 & 12 & 24,5 \\
8,14 a 9,50 & 13 & 26,5 \\
9,51 a 11,25 & 12 & 24,5 \\
\hline & 12 & 24,5 \\
Faixa & 2009 & \% de municípios \\
\hline 3,99 a 6,39 & № de municípios & 25,4 \\
6,40 a 7,90 & 15 & 25,4 \\
7,90 a 9,35 & 15 & 25,4 \\
9,36 a 11,60 & 15 & 23,7 \\
\hline
\end{tabular}

Nota. Fonte: Dados da pesquisa.

As informações apresentadas anteriormente nas Tabelas 2 a 6 permitem descrever que, em geral, os munícipios auditados em 2008 e 2009 estão concentrados na região Nordeste e são mais carentes que a média nacional. Ademais, sua população possui um baixo grau de escolaridade, visto que uma parte significativa, na idade de 18 anos, ainda não completou o ensino médio e apresenta taxa de analfabetismo média de 26,27 e 25,95, respectivamente, nos períodos de 2008 e 2009.

\subsection{Análises das irregularidades}

As irregularidades mencionadas nos relatórios da CGU foram segregadas de acordo com a origem do recurso. Por isso serão descritas para cada Ministério Presidencial. Os recursos auditados são de transferências oriundas dos Ministérios das Cidades, da Saúde e da Integração Nacional. Salienta-se que existem municípios que receberam recursos dos três ministérios. Por meio da Tabela 7 é possível visualizar a quantitativo de municípios que obtiveram recursos em cada Ministério. Vale ressaltar que o Ministério das Cidades teve o maior número de municípios contemplados com recursos do PAC I. 
Tabela 7

Quantidade dos Municípios auditados pela CGU conforme distribuição de recursos por Ministérios

\begin{tabular}{cccc}
\hline Ministério & Das Cidades & Da Saúde & Da Integração Nacional \\
\hline $\mathbf{2 0 0 8}$ & 32 & 29 & 3 \\
2009 & 43 & 28 & 4 \\
\hline
\end{tabular}

Nota. Fonte: Dados da Pesquisa.

$\mathrm{Na}$ Tabela 8 informam-se os percentuais de irregularidades constatados para cada município auditado no ano 2008 por Ministério (Das Cidades, Da Saúde e da Integração Nacional). Em geral, os recursos empregados nos projetos vinculados ao Ministério das Cidades foram destinados para a construção e melhorias na área de habitação dos municípios e são provenientes da primeira etapa do PAC. No caso do Ministério das Cidades, na categoria desperdício ativo, as variáveis com os maiores percentuais foram "Superfaturamento", com $12,50 \%$, e "Licitação Fraudada", com 9,4\%. No que tange às irregularidades da modalidade de desperdício passivo, os fatos que apresentaram os maiores percentuais foram "Má administração", com 62,50\%, "Licitação Irregular", com 31,30\%, "Falta de Publicidade", com $25,00 \%$, e "Irregularidade não relacionada ao agente executor", com 21,90\%.

Em relação ao Ministério da Saúde, a maioria dos recursos do PAC foi empregada para melhorar o saneamento básico dos municípios. Na Tabela 8 nota-se que para o desperdício ativo todos os tipos de irregularidades obtiveram o mesmo percentual, 3,4\%. Já na modalidade de desperdício passivo as constatações com os maiores percentuais foram "Má Administração" (69\%), "Execução Irregular de Programas Sociais" (27,60\%), "Irregularidade não relacionada ao agente executor" (24,10\%) e "Licitação Irregular" (20,70\%).

Para o Ministério da Integração Nacional os recursos do PAC foram empregados nos projetos de implantação, ampliação ou melhoria do esgotamento sanitário em municípios que abrangem as bacias do Rio São Francisco e Paraíba. Pode-se verificar, na Tabela 8, que na categoria desperdício ativo, a variável "Superfaturamento" $(33,30 \%)$ apresentou maior percentual. Já na categoria desperdício passivo, as variáveis que apresentaram os maiores percentuais foram "Má Administração" (100\%) e "Licitação Irregular" (66,7\%).

Tabela 8

Detalhamento dos tipos de desperdícios em percentual de municípios analisados por Ministério - 2008

\begin{tabular}{lccc}
\hline \multicolumn{1}{c}{ Categoria de Desperdícios } & Das Cidades & Da Saúde & $\begin{array}{c}\text { Da Integração } \\
\text { Nacional }\end{array}$ \\
\hline \multicolumn{1}{c}{ Desperdício Ativo } & \% de Municípios & $\begin{array}{c}\text { \% de } \\
\text { Municípios }\end{array}$ & \% de Municípios \\
Superfaturamento & 12,50 & 3,40 & 33,30 \\
Licitação Fraudada & 9,40 & 3,40 & 0,00 \\
Licitação com Desvio de recurso & 0,00 & 3,40 & 0,00 \\
Desvio de Recurso & 0,00 & 3,40 & 0,00 \\
$\quad$ Desperdício Passivo & & & 100,00 \\
Má Administração & 62,50 & 69,00 & 0,00 \\
Execução Irregular de Programas Sociais & 12,50 & 27,60 & 33,30 \\
Irregularidade não Relacionada ao Agente & 21,90 & 24,10 & 66,70 \\
Executor & 31,30 & 20,70 & 0,00 \\
Licitação Irregular & 0,00 & 10,30 & 33,30 \\
Não Ocorreu Contrapartida & 9,40 & 6,90 & 0,00 \\
Obra inacabada ou com execução irregular & 3,10 & 6,90 & 0,00 \\
Elefante Branco & 0,00 & 6,90 & 0,00 \\
Obra Acabada com Irregularidade & 0,00 & 3,40 & 0,00 \\
Inexistência ou Fraca Atuação do Conselho & 0,00 & 3,40 & Continua \\
Desvio de Finalidade para Outro Setor & & & \\
\hline
\end{tabular}


Tabela 8 (continuação)

\begin{tabular}{lccc}
\hline \multicolumn{1}{c}{ Categoria de Desperdícios } & Das Cidades & Da Saúde & Da Integração Nacional \\
\hline \multicolumn{1}{c}{ Desperdício Passivo } & \% de Municípios & \% de Municípios & \% de Municípios \\
Desvio de Finalidade para um Mesmo Setor & 0,00 & 3,40 & 0,00 \\
Falta de Publicidade & 25,00 & 0,00 & 33,30 \\
Licitação com Falta de Concorrência & 3,10 & 0,00 & 0,00 \\
Não Pagamento do Tributo & 0,00 & 0,00 & 0,00 \\
Não execução do recurso & 3,10 & 0,00 & 0,00 \\
Clientelismo & 0,00 & 0,00 & 0,00 \\
Licitação Fracionamento & 0,00 & 0,00 & 0,00 \\
\hline
\end{tabular}

Nota. Fonte: Dados da pesquisa.

O percentual de irregularidades constatadas para cada município auditado referente ao ano de 2009 é apresentado na Tabela 9, de acordo com os três ministérios analisados. De modo geral, os recursos destinados pelos Ministérios das Cidades, da Saúde e da Integração Nacional aos municípios foram empregados nas mesmas atividades do ano de 2008.

Para o Ministério das Cidades, na modalidade de desperdício ativo, é informado na Tabela 9 que as irregularidades com os maiores percentuais foram "Superfaturamento" (14\%), "Desvio de recurso" (7\%) e Licitação Fraudada (4,7\%). Para desperdício passivo, as constatações com os maiores percentuais foram "Má Administração" (62,8\%), "Falta de Publicidade" (44,2\%) e Licitação Irregular (39,5\%).

$\mathrm{Na}$ Tabela 9, observa-se, na categoria desperdício ativo, que as irregularidades com os maiores percentuais foram "Superfaturamento", com 17,9\%, "Licitação Fraudada" e "Desvio de Recursos", ambas com 3,6\%, para o Ministério da Saúde. No que tange às irregularidades na modalidade de desperdício passivo, os fatos que apresentaram maiores percentuais nos municípios analisados foram "Má Administração" (82,10\%), "Execução Irregular de Programas Sociais" (21,4\%) e "Licitação Irregular" (17,9\%).

Quanto ao Ministério da Integração Nacional, é informado na Tabela 9 que, na categoria desperdício ativo, as variáveis "Superfaturamento" e "Desvio de Recursos" representam igualmente $25 \%$ dos municípios analisados. Já, na modalidade desperdício passivo, as categorias que apresentaram maior percentual de constatação foram "Má Administração" com $75 \%$, "Licitação Irregular" e "Obra inacabada ou com execução irregular", ambas com 25\%.

Tabela 9

Detalhamento dos tipos de desperdícios em percentual de municípios analisados por Ministério - 2009

\begin{tabular}{lccc}
\hline \multicolumn{1}{c}{ Categoria de Desperdícios } & Das Cidades & Da Saúde & $\begin{array}{c}\text { Da Integração } \\
\text { Nacional }\end{array}$ \\
\hline \multicolumn{1}{c}{ Desperdício Ativo } & $\begin{array}{c}\text { \% de } \\
\text { Municípios }\end{array}$ & $\begin{array}{c}\text { \% de } \\
\text { Municípios }\end{array}$ & $\begin{array}{c}\text { \% de Municípios } \\
\text { Superfaturamento }\end{array}$ \\
Licitação Fraudada & 14 & 17,9 & 25 \\
Licitação com Desvio de recurso & 4,7 & 3,6 & 0 \\
Desvio de Recurso & 0 & 0 & 0 \\
$\quad$ Desperdício Passivo & 7 & 3,6 & 25 \\
Má Administração & & & 75 \\
Execução Irregular de Programas Sociais & 62,8 & 82,1 & 0 \\
Irregularidade não Relacionada ao Agente & 4,7 & 21,4 & 0 \\
Executor & 25,6 & 7,1 & 25 \\
Licitação Irregular & 39,5 & 17,9 & 0 \\
Não Ocorreu Contrapartida & 2,3 & 0 & Continua \\
\hline
\end{tabular}


Tabela 9 (continuação)

\begin{tabular}{lccc}
\hline \multicolumn{1}{c}{ Categoria de Desperdícios } & Das Cidades & Da Saúde & Da Integração Nacional \\
\hline Desperdício Passivo & \% de Municípios & \% de Municípios & \% de Municípios \\
Obra inacabada ou com execução irregular & 4,7 & 7,1 & 25 \\
Elefante Branco & 0 & 0 & 0 \\
Obra Acabada com Irregularidade & 4,7 & 0 & 0 \\
Inexistência ou Fraca Atuação do Conselho & 4,7 & 0 & 0 \\
Desvio de Finalidade para Outro Setor & 0 & 0 & 0 \\
Desvio de Finalidade para um Mesmo Setor & 0 & 0 & 0 \\
Falta de Publicidade & 44,2 & 10,7 & 0 \\
Licitação com Falta de Concorrência & 0 & 0 & 0 \\
Não Pagamento do Tributo & 2,3 & 3,6 & 0 \\
Não execução do recurso & 11,6 & 0 & 0 \\
Clientelismo & 0 & 0 & 0 \\
Licitação Fracionamento & 2,3 & 3,6 & 0 \\
\hline
\end{tabular}

Nota. Fonte: Dados da pesquisa.

Os resultados das Tabelas 8 e 9 evidenciam possíveis ineficiências decorrentes da gestão realizada pelos responsáveis em administrar os recursos repassados pelo PAC. Conforme apresentado anteriormente, na categoria desperdício ativo foram constatadas as maiores frequências nas irregularidades "Superfaturamento" e "Licitação Fraudada". É um exemplo de superfaturamento, quando os auditores constataram a compra de itens por preços acima dos praticados pelo mercado. Na categoria licitação fraudada, as irregularidades foram encontradas quando haviam evidências de que o processo licitatório foi direcionado a uma organização que possuía ligação de parentesco com um agente político.

De modo recorrente foram observados nos relatórios da CGU, dos anos de 2008 e 2009, na categoria desperdício passivo, os seguintes exemplos de má administração: irregularidades na documentação dos projetos enviados pela prefeitura para obter recursos advindos do PAC e morosidade por parte da prefeitura na regularização das pendências apontadas nos contratos de repasses firmados entre a prefeitura e o órgão competente para gerir os recursos do programa. Outro tipo de irregularidade frequente foi a "Licitação Irregular", que ocorreu, principalmente, em virtude da realização do processo licitatório antes da aprovação do projeto básico pelo órgão responsável e da ausência de evidências de ter ocorrido análise dos custos da obra a ser executada, a fim de dar suporte à verificação das propostas apresentadas nos processos licitatórios. Ressalta-se que existe a possibilidade de que a ausência de pessoal com conhecimento adequado da Lei de Licitação seja a razão para o relevante percentual da irregularidade "Licitação Irregular".

Quanto à "Irregularidade não relacionada ao agente executor", que são irregularidades cometidas por órgãos habilitados em selecionar os municípios que serão beneficiados pelos programas do PAC, foi observado nos relatórios da CGU que tais irregularidades, de modo geral, ocorreram devido à demora na análise da documentação enviada pelo agente executor (na maioria dos casos o agente executor são as prefeituras) interessado em obter recursos provenientes do PAC. Tal situação indica problemas na gestão por parte desses órgãos, o que compromete a efetiva execução das obras e tem como consequência o não atendimento ao objetivo do programa.

A "Falta de Publicidade" foi um tipo recorrente de irregularidade constatada pela CGU nos relatórios de auditoria do PAC1. Tal irregularidade ocorreu quando a prefeitura deixou de notificar os partidos políticos, sindicatos de trabalhadores e entidades empresariais, quanto ao repasse de verba advinda da União para execução de obras no município. A falta de cuidado em dar publicidade na execução dos recursos indica uma possível ausência na geração de transparência dos atos e ações da prefeitura. Além disso, merece ser investigado se a "Falta de Publicidade" foi intencional ou por deficiências na gestão administrativa, em virtude do descumprimento dos ritos mínimos exigidos pela legislação pública. 
Quanto a "Execução Irregular de Programas Sociais", foram observados com frequência nos relatórios da CGU a duplicidade de beneficiários, beneficiários que não atendem aos requisitos do programa e desatualização do cadastro de beneficiários dos programas.

Ademais, conforme mencionado anteriormente, verificou-se constantemente nos relatórios de auditoria da CGU a irregularidade "Obra inacabada ou com execução Irregular". Exemplo dessa irregularidade é a execução de itens da obra fora das especificações do projeto básico aprovado para ser executado, e obras atrasadas.

\section{CONCLUSÃO}

O objetivo do estudo foi analisar as irregularidades constatadas pela CGU na aplicação dos recursos federais destinados às áreas de saneamento e habitação dos municípios brasileiros por meio da primeira etapa do PAC. Neste estudo, as irregularidades constatadas pelos auditores da CGU foram classificadas em desperdício ativo e passivo. Utilizou-se os relatórios de fiscalização da CGU e os dados relativos ao Censo 2000, disponibilizados pelo IBGE. Optou-se por realizar procedimentos de análise de conteúdo e descritivos a fim de atingir o objetivo proposto.

Observa-se que os municípios que constituem o objeto de análise desta pesquisa, apresentam um perfil de carência social, se comparados à média nacional, e possuem uma população com baixo grau de escolaridade. É possível que o perfil desses municípios possa contribuir para o alto percentual de desperdício ativo e passivo, evidenciado nas análises apresentadas. Estudos anteriores demonstram que a situação de vulnerabilidade socioeconômica dos municípios pode ser propícia para a maior ocorrência de corrupção e má gestão. Nesse sentido, Mendes (2004), baseando-se em Mendes (2001), argumenta que há indícios de que casos de irregularidades e má gestão concentrem-se em municípios vulneráveis, com baixa escolaridade e condições de vida. Ainda, Vieira (2011) salienta que a corrupção pode ter efeitos negativos sobre o bem-estar social. Em seu estudo, o referido autor constatou que existe uma associação negativa, estatisticamente significativa, entre o IDHM e as falhas constatadas pela CGU nos municípios auditados.

Em relação ao perfil dos desperdícios, observa-se que as irregularidades que apresentaram um maior percentual de constatações são as classificadas como desperdício passivo, com destaque para a irregularidade classificada como "Má administração", que apresentou o maior percentual nos três ministérios analisados. Esse resultado corrobora com os achados de Dias et. al (2013) e Marin et. al (2014). Em seu trabalho, Dias et. al (2014) salientam a necessidade de maior preocupação com os desperdícios passivos, pois, segundo os autores, esse tipo de desperdício não recebe a devida atenção dos órgãos responsáveis, da academia e da população. Entretanto, os autores argumentam que tais desperdícios afetam significativamente a qualidade dos serviços oferecidos à população e causam prejuízos aos cofres públicos.

Ademais, é válido destacar, que o cenário constatado, em 2008 e 2009, pelos auditores da CGU nas obras do PAC1, via edição especial do PFPS, ainda persiste. Em novo levantamento realizado, em 2015, pelo ITB, em 183 obras de esgotamento sanitário (110 referentes ao PAC1 e 71 ao PAC2), observou-se que apenas $32 \%$ das obras estavam concluídas e que os fatores que geraram atrasos e paralisações são os mesmos constatados em levantamentos anteriores realizados pelo ITB. São eles: deficiências na qualidade dos projetos originalmente enviados ao governo federal, problemas nas licitações, burocracia no repasse dos recursos, lentidão no processo de concessão de licenças ambientais, entre outros aspectos (ITB, 2016). Diante disso, verifica-se que os órgãos responsáveis pelo PAC não tomaram providências a fim de corrigir as irregularidades constatadas, em 2008 e 2009, pelos auditores da CGU, nas obras do PAC1, o que pode comprometer o desempenho das ações realizadas no âmbito do programa.

Por fim, sugere-se para futuras pesquisas verificar a existência de associação entre o perfil dos municípios auditados e as irregularidades constatadas pela CGU, além da reaplicação deste estudo em outras áreas auditadas pela CGU e uma avaliação do grau de atuação do controle social versus o nível de ocorrência de irregularidades. 


\section{NOTAS}

${ }^{1}$ Considerado a primeira etapa do PAC. Também denominado de PAC1.

2 Para construção dos indicadores de corrupção e má gestão, Ferraz et al. (2008) não utilizaram os relatórios de auditorias provenientes dos sorteios $8,11,12,13$ e 15, uma vez que não estavam disponíveis quando a pesquisa foi realizada.

\section{REFERÊNCIAS}

Bandiera, O., Prat, A., \& Valletti, T. (2009). Active and passive waste in government spending: evidence from a policy experiment. American Economic Review, 99(4), 1278-1308. doi: 10.1257/aer.99.4.1278

Bardin, L. (1977). Análise de Conteúdo. Tradução de Luis Antero Reto e Augusto Pinheiro. Lisboa: Edições 70.

Caldas, O. V., Costa, C. M., \& Pagliarussi, M. S. (2016). Corrupção e composição dos gastos governamentais: evidências a partir do Programa de Fiscalização por Sorteios Públicos da Controladoria-Geral da União. Revista de Administração Pública, 50(2), 237-264. doi: http://dx.doi.org/10.1590/0034-7612140185

Controladoria Geral da União. (2017a). Auditoria e Fiscalização. Recuperado em 25 setembro, 2017 de http://www.cgu.gov.br/assuntos/auditoria-e-fiscalizacao.

Controladoria Geral da União. (2009). Notícias. Recuperado em 25 setembro, 2017 de http://www.cgu.gov.br/noticias/2009/03/segundo-sorteio-especial-do-pac-sera-realizadoamanha-pela-cgu.

Controladoria Geral da União. (2017b). Programa de Fiscalização por Sorteios Públicos. Recuperado em 25 setembro, 2017 de https://auditoria.cgu.gov.br

Dias, L. N. S., Matias-Pereira, J., Farias, M. R. S., \& Pamplona, V. M. S. (2013). Fatores Associados ao Desperdício de Recursos da Saúde Repassados pela União aos Municípios Auditados pela Controladoria Geral da União. R. Cont. Fin-USP, 24(63), 206-218. doi: http://dx.doi.org/10.1590/S1519-70772013000300004

Di Tella, R., \& Schargrodsky, E. (2003). The role of wages and auditing during a crackdown on corruption in the city of Buenos Aires. Journal of Law and Economics, 46(1), 269-92. doi: 10.2139/ssrn.269490

Ferraz, C., Finan; F., \& Moreira, D. B. (2008). Corrupção, má gestão, e desempenho educacional: evidências a partir da fiscalização dos municípios. Anais do Encontro Nacional de Economia, Salvador, BA, Brasil, 36.

Hart, O., Shleifer, A., \& Vishny, R. W. (1997). The proper scope of government: Theory and an application to prisons. The Quarterly Journal of Economics, 112(4), 1127-61. doi: 10.1162/003355300555448

Instituto Brasileiro de Geografia e Estatísticas. (2017). Censo 2000: características da população e dos domicílios. Recuperado em 25 setembro, 2017 de http://www.ibge.gov.br/home/estatistica/populacao/censo2000/

Instituto Trata Brasil (2013). Acompanhamento do PAC Saneamento em 2012 análise comparativa com 2009, 2010 e 2011. Recuperado em 25 setembro, 2017 de http://www.tratabrasil.org.br/datafiles/uploads/deolhonopac/relatorio-de-olho-no-PAC2013.pdf

Instituto Trata Brasil (2016). Relatório - 7 anos de Acompanhamento do PAC saneamento: 2009 a 2015. Recuperado em 09 outubro, 2017 de http://www.tratabrasil.org.br/datafiles/de-olhono-pac/2016/relatorio.pdf?pdf=Relatorio-Completo_De-Olho-No-PAC-16 
Marin, T. I. S., Gama, D. S. S., \& Campelo, S. (2014). Corrupção e Ineficiência nos Repasses Federais: uma análise dos gastos do Ministério das Cidades nos Municípios Paraenses (2003-2013). Anais do Congresso USP de Iniciação Científica em Contabilidade, São Paulo, SP, Brasil, 11.

Mendes, M. (2004). Análise das irregularidades na administração municipal do FUNDEF: Constatações do programa de fiscalização a partir de sorteios públicos da ControladoriaGeral da União, Transparência Brasil.

Mendes, M. (2001). Descentralização do ensino fundamental: avaliação de resultados do FUNDEF. Planejamento e Políticas Públicas, 24(2001), 27-52.

Ministério do Planejamento, Orçamento e Gestão (2010). Programa de Aceleração do Crescimento. 11ำ Balanço do PAC. Recuperado em 25 setembro, 2017 de http://www.pac.gov.br/pub/up/relatorio/6c57986d15d0f160bc09ac0bfd602e74.pdf

Ministério do Planejamento, Orçamento e Gestão. (2017). Programa de Aceleração do Crescimento: 2007-2010. Recuperado em 25 setembro, 2017 de http://www.planejamento.gov.br/apresentacoes/2007/070122_pac_medidas_institucionais .pdf/view

Programa Nacional das Nações Unidas para o Desenvolvimento. (2017) Evolução do Desenvolvimento Humano nos Municípios Brasileiros. Recuperado em 25 setembro, 2017 de http://www.atlasbrasil.org.br/2013/data/rawData/idhm-do-brasil.pdf

Vieira, James, B. (2011). O impacto das capacidades institucionais do setor público: um estudo exploratório sobre as causas e efeitos das impropriedades na administração pública municipal brasileira. $6^{\circ}$ concurso de monografia da CGU, 107- 159. 